\title{
$\mathrm{BMJ}$
}

\section{Use of weaning protocols for reducing duration of mechanical ventilation in critically ill adult patients: Cochrane systematic review and meta-analysis}

\author{
Bronagh Blackwood, lecturer in nursing,, Fiona Alderdice, director, ${ }^{1}$ Karen Burns, clinician scientist, ${ }^{2}$ Chris \\ Cardwell, lecturer in medical statistics, ${ }^{3}$ Gavin Lavery, consultant in intensive care medicine, ${ }^{4}$ Peter \\ O’Halloran, lecturer in nursing ${ }^{1}$
}

${ }^{1}$ Nursing and Midwifery Research Unit, Queen's University Belfast, Belfast, BT9 5BN, Northern Ireland

${ }^{2}$ St Michael's Hospital, Interdepartmental Division of Critical Care Medicine, Toronto, Ontario, Canada

${ }^{3}$ Centre for Public Health, Queen's University Belfast, Belfast

${ }^{4}$ Belfast Health and Social Care Trust, Royal Victoria Hospital,

Belfast, Belfast

Correspondence to: B Blackwood b.blackwood@qub.ac.uk

Cite this as: BMJ 2011;342:C7237 doi:10.1136/bmi.c7237

\section{ABSTRACT}

Objective To investigate the effects of weaning protocols on the total duration of mechanical ventilation, mortality, adverse events, quality of life, weaning duration, and length of stay in the intensive care unit and hospital.

Design Systematic review.

Data sources Cochrane Central Register of Controlled Trials, Medline, Embase, CINAHL, LILACS, ISI Web of Science, ISI Conference Proceedings, Cambridge Scientific Abstracts, and reference lists of articles. We did not apply language restrictions.

Review methods We included randomised and quasirandomised controlled trials of weaning from mechanical ventilation with and without protocols in critically ill adults.

Data selection Three authors independently assessed trial quality and extracted data. A priori subgroup and sensitivity analyses were performed. We contacted study authors for additional information.

Results Eleven trials that included 1971 patients met the inclusion criteria. Compared with usual care, the geometric mean duration of mechanical ventilation in the weaning protocol group was reduced by $25 \%$ (95\% confidence interval $9 \%$ to $39 \%, \mathrm{P}=0.006 ; 10$ trials); the duration of weaning was reduced by $78 \%$ ( $31 \%$ to $93 \%$, $\mathrm{P}=0.009$; six trials); and stay in the intensive care unit length by $10 \%$ ( $2 \%$ to $19 \%, P=0.02$; eight trials). There was significant heterogeneity among studies for total duration of mechanical ventilation $\left(I^{2}=76 \%, P<0.01\right)$ and duration of weaning $\left(1^{2}=97 \%, P<0.01\right)$, which could not be explained by subgroup analyses based on type of unit or type of approach.

Conclusion There is evidence of a reduction in the duration of mechanical ventilation, weaning, and stay in the intensive care unit when standardised weaning protocols are used, but there is significant heterogeneity among studies and an insufficient number of studies to investigate the source of this heterogeneity. Some studies suggest that organisational context could influence outcomes, but this could not be evaluated as it was outside the scope of this review.

\section{INTRODUCTION}

Observational studies have shown that prolonged mechanical ventilation of critically ill patients is associated with adverse clinical outcomes. Patients who are slower to breathe without mechanical ventilation have higher rates of mortality ${ }^{12}$ and morbidity, including ventilator associated pneumonia ${ }^{3-5}$ and ventilator associated lung injury. ${ }^{6-8}$ Mechanical ventilation should therefore probably be discontinued as soon as patients are capable of breathing independently. Moreover, patients who are dependent on a ventilator generally remain in intensive care, requiring specialised care and frequent monitoring. In the current climate of limited availability of intensive care beds, maximising the use of limited intensive care resources (including nursing and equipment costs) is an important goal of providing care to critically ill patients. For these reasons, discontinuing mechanical ventilation in a timely and safe way should lead to desirable outcomes for patients and clinicians alike, and strategies that assist discontinuation should be robustly evaluated.

The process leading to discontinuing mechanical support is known as weaning. Identifying when the patient is ready to wean and deciding on the most appropriate method of weaning is influenced by the judgment and experience of the doctor. ${ }^{9}$ Doctors tend to underestimate the probability of successfully stopping mechanical ventilation ${ }^{10}$ and predictions, based on judgment alone, have low sensitivity (ability to predict success) and specificity (ability to predict failure). ${ }^{11}$ Until recently, there have been few standards of care in this area that are based on scientifically sound data. As a result, wide variation exists in weaning practice. There are several options, or weaning methods, for decreasing support. They include intermittent $\mathrm{T}$ piece trials involving short time periods of spontaneous breathing through a $\mathrm{T}$ piece circuit while the patient is still intubated; synchronised intermittent mechanical ventilation involving gradual reductions in the ventilator rate, by increments of 1 to 4 breaths/min; pressure support ventilation involving the gradual reduction of pressure by increments of 2 to $6 \mathrm{~cm} \mathrm{H}_{2} \mathrm{O}$; spontaneous breathing 


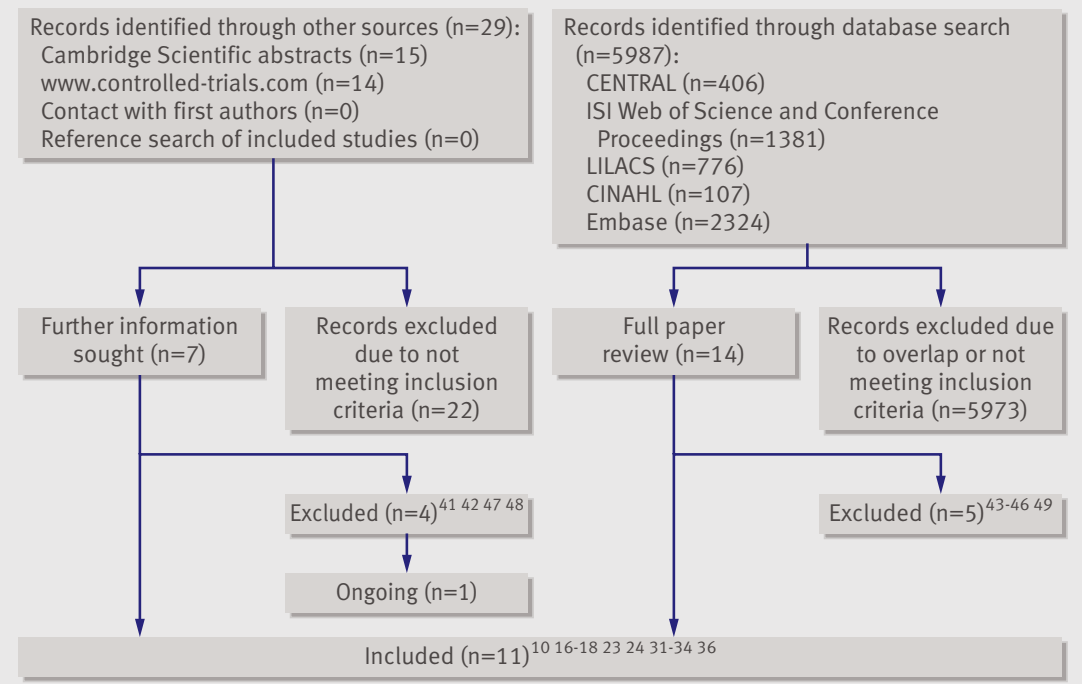

Fig 1| Identification of studies on weaning from mechanical ventilation

through a ventilator circuit with the application of continuous positive airway pressure; and combinations of these and newer options, such as bi-level positive airway pressure. The evidence is equivocal as to which method is superior, though it has been suggested that synchronised intermittent mechanical ventilation is the least effective method. ${ }^{12-14}$

Doctors have different experiences, skills, and weaning philosophies, and, in view of the potential for variation, there has been an increasing interest in providing more consistent practice in intensive care units by developing weaning protocols that provide structured guidance. Protocols are intended to improve efficiency of practice by following an expert consensus to reduce variation produced by the application of individual judgment and experience. ${ }^{15}$ In general, there are three components to a weaning protocol. The first component is a list of objective criteria (often referred to as "readiness to wean" criteria) based on general clinical factors to help to decide if a patient is ready to breathe without the help of a ventilator, such as that used by Ely and colleagues. ${ }^{16}$ The second component consists of structured guidelines for reducing ventilatory support. This might be abrupt (for example, spontaneous breathing trials on a $\mathrm{T}$ piece) or gradual with a stepwise reduction in mechanical support (for example, synchronised intermittent mechanical ventilation or pressure support ventilation) such as that used by Brochard et al ${ }^{12}$ Esteban et al,${ }^{14}$ Kollef et $\mathrm{al},{ }^{17}$ and Marelich et al. ${ }^{18}$ The third component is a list of criteria for deciding if the patient is ready for extubation, such as that used by Hendrix et al. ${ }^{19}$ In many intensive care units, protocols are presented as written guides or algorithms, and ventilator settings are manually adjusted by healthcare professionals. More recently, progress in ventilator microprocessor technology has enabled the development of computer assisted management of ventilation and weaning. Computerised ventilatory management adapts the ventilator output to the patient's needs with closed loop systems. These systems measure and interpret respiratory data in real time and provide continual adjustment of the level of assistance within targeted values. It is suggested that through enabling "interaction" between the patient and the ventilator, the closed loop systems can improve tolerance of mechanical ventilation and reduce the work of breathing. ${ }^{20}$ Multiple commercial computerised ventilation and weaning programs have been developed, including adaptive support ventilation, proportional assist ventilation, and pressure support ventilation (SmartCare). ${ }^{21}$

Several studies have explored the use of weaning protocols in clinical practice and shown that they can be safe and effective in reducing the time spent on mechanical ventilation. ${ }^{22}$ Other studies in various populations, however, have not shown benefit. ${ }^{23-25}$ The discordant results of these studies might reflect the fact that protocols vary in more ways than in composition alone. While many protocols include criteria for readiness to wean and guidelines for reducing ventilator support, the specific criteria and guidance vary. Furthermore, not all protocols include extubation criteria. Protocols are implemented in different environments by healthcare professionals (including nurses, respiratory therapists, and doctors) and by automated (computerised) systems. Limited evidence suggests that nurses and allied health professionals might adhere to protocols more than physicians. ${ }^{26}$ Consequently, recent studies have compared weaning protocols led by nurses or respiratory therapists with traditional or medical directed weaning. ${ }^{16-18}$

We synthesised the best current evidence for the effectiveness of weaning protocols compared with no protocols in weaning critically ill adults from invasive mechanical ventilation. The protocol and the review can be found in the Cochrane Database of Systematic Reviews. ${ }^{27}$

\section{METHODS}

Criteria for inclusion of studies

Studies and participants

We included randomised and quasi-randomised controlled trials. The study population included adults receiving invasive mechanical ventilation with a nasotracheal or orotracheal tube. We excluded studies in children, non-invasive ventilation as a weaning strategy, or patients with tracheotomies.

\section{Interventions}

Weaning per protocol was defined as a method of limiting the duration of invasive ventilation that included at least the first two of: a list of objective criteria based on general clinical factors for deciding if a patient is ready to discontinue mechanical ventilation; structured guidelines for reducing ventilatory support, such as a trial of spontaneous breathing or a stepwise reduction in support (for example, synchronised intermittent mechanical ventilation or pressure support ventilation); and a list of criteria for deciding if the patient is ready for extubation. 
Table 1|Characteristics of studies on weaning from mechanical ventilation excluded analysis

Reason for exclusion

Beale et al, $2008^{41}$

Control group subject to weaning protocol

Butler et al, $2007^{42}$ Trial stopped because of recruitment problems, unable to obtain data

Donglemans et al, $2009^{43}$ Control group subject to weaning protocol

East et al, $1999^{44}$ Unable to identify weaning practice in control group

Lellouche et al, $2006^{45}$

McKinley et al, $2001^{46}$

Papirov et al, $2008^{47}$

Scholz et al, $2008^{48}$

Taniguchi et al, $2009^{49}$

Control group subject to weaning protocol

Unable to identify weaning practice in control group

Control group subject to weaning protocol

Control group subject to weaning protocol

Control group subject to weaning protocol
We did not exclude studies that did not include formal extubation criteria as not all studies included this component. Furthermore, delay in extubation can be caused by organisational factors and not necessarily by delays in weaning. Usual weaning practice was defined as the usual practice in an intensive care unit (as stated by the authors) where no written guidelines were applied.

\section{Outcome measures}

The primary outcome measure was the duration of mechanical ventilation. Secondary outcome measures included mortality (intensive care unit and hospital); adverse events (re-intubation, tracheostomy, protracted mechanical ventilation); weaning duration; length of stay in intensive care unit; length of stay in hospital; and cost.

\section{Search methods for identification of studies}

We used the standard search strategy of the Cochrane Anaesthesia Review Group of the Cochrane Collaboration. The search included the Cochrane Central Register of Controlled Trials (CENTRAL) (Cochrane Library 2010, Issue 1), Medline (1950 to January 2010), Embase (1988 to January 2010), CINAHL (1937 to January 2010), ISI Web of Science and Conference Proceedings (1970 to January 2010), and LILACS (1982 to January 2010). The search strategy and terms are detailed in the online review at http://onlinelibrary. wiley.com/o/cochrane/clsysrev/articles/CD006904/ frame.html. In addition, we searched reference lists of all identified study reports, contacted authors for further information on ongoing trials, and searched the meta-register of controlled trials at www.con trolled-trials.com. No language restrictions were applied.

\section{Selection of studies, data extraction, and quality assessment}

Two authors (BB and $\mathrm{POH}$ ) independently scanned titles and abstracts identified by electronic searching, manual searches, and contacts with experts. Three authors (BB, $\mathrm{KB}, \mathrm{POH}$ ) retrieved and evaluated the full text versions of potentially relevant studies and independently extracted data using a modified paper version of the Cochrane Anaesthesia Review Group's data extraction form (version 3 January 2007). Data were extracted on study design, setting and participants, inclusion and exclusion criteria, and interventions and outcomes. In addition, we assessed risk of bias using the Cochrane Collaboration's domain based evaluation tool for assessing the risk of bias. ${ }^{28} \mathrm{We}$ assessed adequacy of the generation of the allocation sequence; concealment of allocation; blinding procedures; whether or not outcome data were adequately addressed; whether the study was free from suggestion of selective outcome reporting; and whether it was free from other problems that could put it at risk of bias. BB contacted authors of included studies if insufficient information was available in the publications to obtain missing data. Disagreement was resolved through consultation with a fourth author (FA).

\section{Data synthesis}

Data were processed in accordance with the Cochrane handbook. ${ }^{29}$ Intervention effects were expressed with odds ratios and 95\% confidence intervals for dichotomous data and mean differences and 95\% confidence intervals for continuous data. The degree of heterogeneity was informally evaluated by visual inspection of forest plots, and more formally by measuring the impact of heterogeneity with the $\mathrm{I}^{2}$ statistic $\left(\mathrm{I}^{2}>50 \%\right.$ indicates significant heterogeneity), and tested with the $\chi^{2}$ statistic $(\mathrm{P}<0.05) .{ }^{30}$ We used a fixed effects model for meta-analysis, except where we identified statistical heterogeneity when we used a random effects model. The data for duration of mechanical ventilation, duration of weaning, and length of stay in the intensive care unit and hospital were skewed so we log transformed these data for the primary analyses. In three studies the authors provided the means and standard deviations on the log scale. ${ }^{163132}$ In four studies in which only means and standard deviations of the un-logged data were available ${ }^{10173334}$ we used approximations to calculate the mean and standard deviation on the log scale using method 1 in Higgins et al. ${ }^{35}$ In four studies we could obtain outcomes reported only as medians and interquartile ranges ${ }^{18232436}$ so we approximated the mean using the median $^{37}$ and calculated approximate standard deviation estimates from the interquartile range on the log scale. ${ }^{38}$ The difference between the intervention and control group in the mean of a variable on the log scale was exponentiated to give the ratio of geometric means of the variable on the un-logged scale. This was generally reported as a percentage increase (or reduction) in geometric mean in the treatment group compared with the control group for ease of understanding (see Bland and Altman ${ }^{39}$ for more details).

We performed a sensitivity analysis to examine two areas of uncertainty. Firstly, we examined the impact of excluding studies with a high risk of bias (in one or more of the six domains) on the total duration of mechanical ventilation and weaning. Secondly, we examined the results using the un-logged data. We performed a subgroup analysis to assess the impact of the approach to delivering the protocol (professional led or computer driven) and type of intensive care unit (medical, surgical, neurological, or mixed) on total 
Table 2 |Summary of included studies of weaning in critically ill adults on mechanical ventilation

\begin{tabular}{|c|c|c|c|c|c|}
\hline Study & Methods & No of patients & Interventions & Outcomes & Country, setting \\
\hline Ely, $1996^{16}$ & RCT & 300 & $\begin{array}{l}\text { Protocol delivered by RNs and RTs } v \text { physician } \\
\text { judgment }\end{array}$ & $\begin{array}{l}\text { Total duration of MV, weaning duration, length of stay in } \\
\text { ICU, adverse events, ICU and hospital costs, length of stay } \\
\text { in hospital, mortality }\end{array}$ & $\begin{array}{l}\text { US, one medical and one } \\
\text { coronary ICU, closed units }\end{array}$ \\
\hline Kollef, $1997^{17}$ & RCT & 357 & $\begin{array}{l}\text { Protocol delivered by RNs and RTs } v \text { physician } \\
\text { judgment }\end{array}$ & $\begin{array}{l}\text { Total duration of MV, reintubation, length of stay in } \\
\text { hospital, hospital mortality, hospital cost, MV time before } \\
\text { weaning, protracted weaning }>7 \text { days }\end{array}$ & $\begin{array}{l}\text { US, two medical and two } \\
\text { surgical ICUs }\end{array}$ \\
\hline Krishnan, $2004^{23}$ & $\begin{array}{l}\text { Quasi- } \\
\text { RCT }\end{array}$ & 299 & $\begin{array}{l}\text { Protocol delivered by RNs and RTs } v \text { physician } \\
\text { judgment }\end{array}$ & $\begin{array}{l}\text { Total duration of MV, duration of SBT preceding MV } \\
\text { discontinuation, length of stay in ICU, location after ICU } \\
\text { discharge, ICU and hospital mortality, reinstitution of MV }\end{array}$ & US, one medical ICU \\
\hline Marelich, $2000^{18}$ & RCT & 335 & $\begin{array}{l}\text { Protocol delivered by RNs and RTs } v \text { physician } \\
\text { judgment (medical ICU) and standardised } \\
\text { approach (surgical ICU) }\end{array}$ & $\begin{array}{l}\text { Total duration of MV, incidence of VAP, weaning duration, } \\
\text { ventilator discontinuation failure rate }\end{array}$ & $\begin{array}{l}\text { US, one medical and one } \\
\text { surgical/trauma ICU }\end{array}$ \\
\hline Namen, $2001^{24}$ & RCT & 100 & Protocol delivered by RTs $v$ practice (not stated) & $\begin{array}{l}\text { Total duration of MV, length of stay in ICU, time to } \\
\text { successful extubation, adverse events, ICU and hospital } \\
\text { costs }\end{array}$ & $\begin{array}{l}\text { US, neurosurgical patient } \\
\text { population }\end{array}$ \\
\hline Navalesi, $2008^{31}$ & RCT & 318 & $\begin{array}{l}\text { Protocol } v \text { daily evaluation and physician } \\
\text { judgment }\end{array}$ & $\begin{array}{l}\text { Rate of extubation, duration of MV, length of stay in ICU and } \\
\text { hospital, ICU mortality, tracheostomy }\end{array}$ & Italy, one closed neuro ICU \\
\hline Piotto, $2008^{34}$ & $\begin{array}{l}\text { Quasi- } \\
\text { RCT }\end{array}$ & 36 & $\begin{array}{l}\text { Protocol delivered by RT } v \text { gradual reduction in } \\
\text { RR and PS possible SBT according to RT } \\
\text { physician judgment }\end{array}$ & $\begin{array}{l}\text { Reintubation rate, length of stay in CCU, time from } \\
\text { intubation to start of weaning, start of weaning to } \\
\text { extubation, SBT to extubation, presence of respiratory } \\
\text { infection in patients requiring reintubation, mortality of } \\
\text { reintubated patients }\end{array}$ & Brazil, one CCU \\
\hline Rose, $2008^{32}$ & RCT & 102 & $\begin{array}{l}\text { Computerised protocol (SmartCare) } v \text { weaning } \\
\text { of PS and PEEP according to usual local practice }\end{array}$ & $\begin{array}{l}\text { Time to separation, total duration of MV, intubation to first } \\
\text { extubation and successful extubation, length of stay in ICU } \\
\text { and hospital, ICU mortality, rate of successful extubation, } \\
\text { rate of reintubation, rate of non-invasive ventilation after } \\
\text { extubation. }\end{array}$ & $\begin{array}{l}\text { Australia, one mixed medical, } \\
\text { surgical, trauma ICU }\end{array}$ \\
\hline Simeone, $2002^{33}$ & RCT & 49 & Protocol $v$ physician judgment & $\begin{array}{l}\text { Total duration of MV, length of stay in ICU, No of } \\
\text { postoperative complications }\end{array}$ & Italy, one cardiac surgical ICU \\
\hline Stahl, $2009^{36}$ & RCT & 60 & $\begin{array}{l}\text { Computerised protocol (SmartCare) } v \text { weaning } \\
\text { of PS according to physician judgment }\end{array}$ & $\begin{array}{l}\text { Duration of ventilator weaning, total duration of MV, length } \\
\text { of stay in ICU, reintubation within } 48 \text { hours, physician and } \\
\text { nursing workload, ICU and hospital mortality }\end{array}$ & Germany, one surgical ICU \\
\hline $\begin{array}{l}\text { Strickland, } \\
1993^{10}\end{array}$ & RCT & 15 & $\begin{array}{l}\text { Computerised protocol (Supersport model) } v \\
\text { SIMV and PS weaning according to physician } \\
\text { judgment }\end{array}$ & $\begin{array}{l}\text { Time spent with RR } 8 \text { or }>30 \text {, time spent with } T V<5 \mathrm{~mL} / \mathrm{kg} \text {, no } \\
\text { of arterial blood gases drawn, weaning duration, MV time } \\
\text { before weaning. }\end{array}$ & US, one medical ICU \\
\hline
\end{tabular}

$\mathrm{RCT}=$ randomised controlled trial; $\mathrm{CCU}=$ coronary care unit; ICU=intensive care unit; $\mathrm{MV}=$ =mechanical ventilation; $\mathrm{PEEP}=$ positive end expiratory pressure; $\mathrm{PS}=$ pressure support; $\mathrm{RN}=$ registered nurse; RR=respiratory rate; RT=respiratory therapists; $S B T=$ spontaneous breathing trial; SIMV=synchronised intermittent mechanical ventilation; TV=tidal volume.

duration of mechanical ventilation. We could not do a subgroup analysis on type of protocol because only two studies used the same protocol. ${ }^{1624}$

The data were entered into Review Manager software by $\mathrm{BB}$, and $\mathrm{POH}$ checked data entry. All analyses were conducted with Review Manager. ${ }^{40}$

\section{RESULTS}

\section{Description of studies}

Search results - The search of electronic databases retrieved 6016 citations: 5987 references from the database search and 29 relevant references from web based sources. After reviewing the titles and abstracts, we identified and retrieved 14 database references in full text for review and obtained further information on seven unpublished trials located on the controlled trials website. Figure 1 summarises the study selection process, and table 1 provides details of excluded studies ${ }^{41-49}$ and reasons for their exclusion.

Included studies -We included 11 studies with 1971 participants (table 2). The sample sizes ranged from 15 to 357 participants. All studies took place in intensive care units in hospitals. Trials were conducted in the United States, ${ }^{1016-182324}$ Brazil, $^{34}$ Italy, ${ }^{3133}$
Germany, ${ }^{36}$ and Australia. ${ }^{32}$ Participants were recruited from various intensive care units including medical, ${ }^{1016-1823}$ coronary, ${ }^{1634}$ surgical, ${ }^{1736}$ surgical/ trauma, ${ }^{18}$ mixed (including medical, surgical/trauma patients), ${ }^{32}$ neurosurgical, ${ }^{2431}$ and cardiac surgical. ${ }^{33}$ Three trials were conducted in multiple units ${ }^{16-18}$ and seven in single units. ${ }^{102331-3436}$ One trial specified the population (neurosurgical) rather than the unit. ${ }^{24}$ Four studies described the ventilatory modes used in "usual practice" in the control group, and these involved a reduction in respiratory rate in synchronised intermittent mechanical ventilation and a reduction in pressure support in pressure support ventilation, ${ }^{1934}$ a reduction in positive end expiratory pressure and pressure support ventilation, ${ }^{32}$ and a reduction in pressure support ventilation. ${ }^{36}$ The seven remaining described usual practice as weaning according to the physician's discretion without describing what this constituted.

Protocols were delivered by registered nurses and respiratory therapists, ${ }^{16-1823}$ respiratory therapists, ${ }^{24}$ or physicians, registered nurses, and respiratory therapists, $^{31}$ or computer driven ${ }^{103236}$ or not stated. ${ }^{334}$ All studies used criteria on readiness to wean for protocol entry, but the criteria varied greatly. 


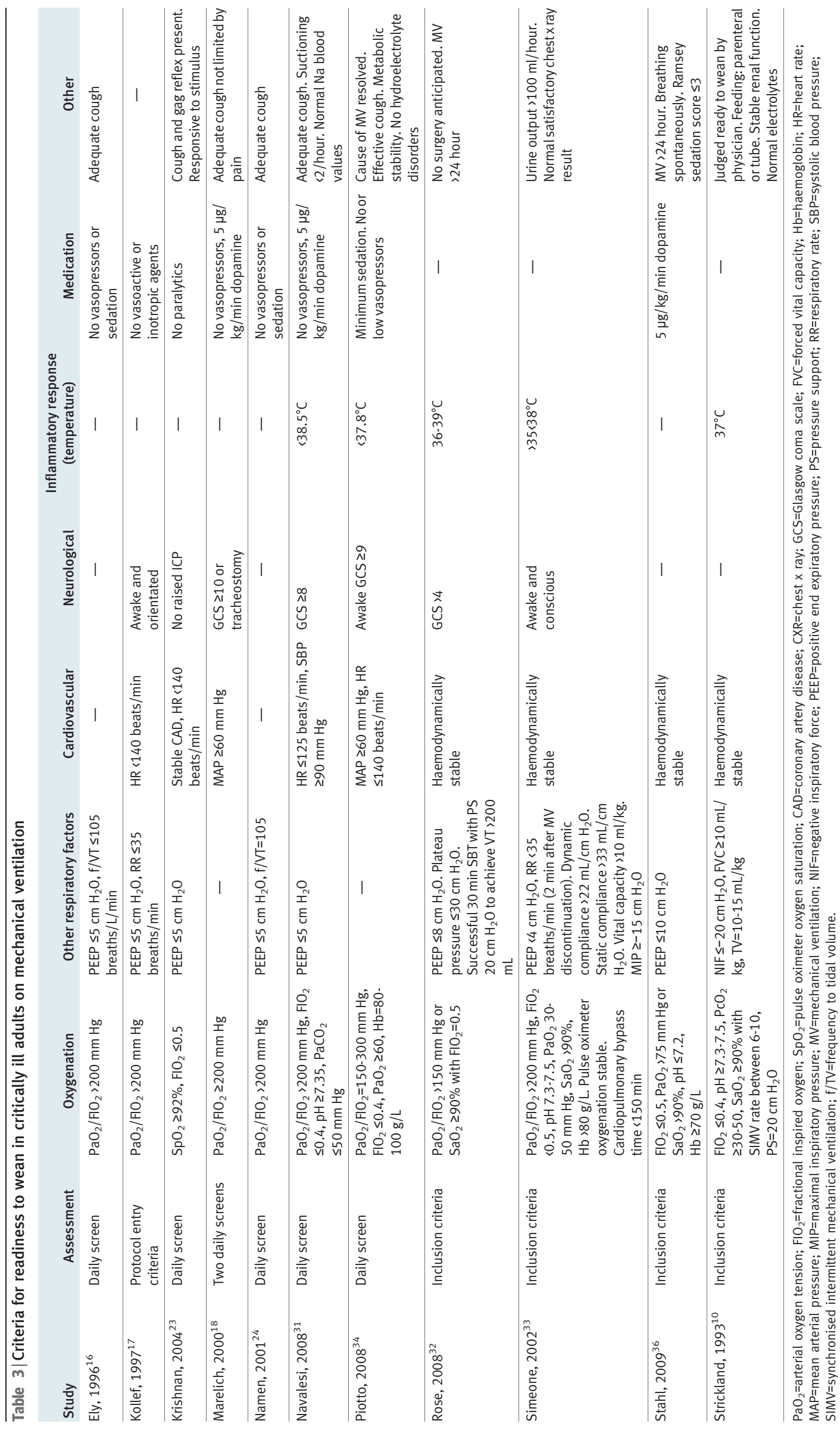


Table $4 \mid$ Characteristics of weaning methods for critically ill adults on mechanical ventilation

\begin{tabular}{|c|c|c|c|}
\hline Study & Screen & Weaning method & $\begin{array}{c}\text { Extubation } \\
\text { criteria }\end{array}$ \\
\hline Ely, $1996^{16}$ & Daily & SBT two hour on CPAP $5 \mathrm{~cm} \mathrm{H}_{2} \mathrm{O}$ & Notify doctor \\
\hline Kollef, $1997^{17}$ & & $\begin{array}{l}\text { SBT 30-60 min on CPAP } 5 \mathrm{~cm} \mathrm{H}_{2} \mathrm{O} \text {, PS to } 6 \mathrm{~cm} \mathrm{H}_{2} \mathrm{O} \text {. PS stepwise reduction to } 6 \mathrm{~cm} \mathrm{H}_{2} \mathrm{O} \text {. } \\
\text { IMV stepwise reduction to } 0 \text { breaths/min, on PEEP } 5 \mathrm{~cm} \mathrm{H}_{2} \mathrm{O} \text { and PS } 6 \mathrm{~cm} \mathrm{H}_{2} \mathrm{O} \text { for } 30-60 \\
\text { min }\end{array}$ & All yes \\
\hline Krishnan, $2004^{23}$ & Daily & SBT one hour on CPAP $5 \mathrm{~cm} \mathrm{H}_{2} \mathrm{O}$ & Notify doctor \\
\hline Marelich, $2000^{18}$ & Twice daily & $\begin{array}{l}\text { ¿72 hour admissions: } S B T 30 \text { min on } P S=8 \mathrm{~cm} \mathrm{H}_{2} \mathrm{O} \text { and } \mathrm{PEEP}=8 \mathrm{~cm} \mathrm{H} \mathrm{H}_{2} \mathrm{O} .>72 \text { hour } \\
\text { admissions: } P E E P, I M V \text {, and PS stepwise reductions to achieve } \mathrm{FIO}_{2} 0.5, P E E P=8 \mathrm{~cm} \mathrm{H}_{2} \mathrm{O} \text {, } \\
\mathrm{IMV}=6 \mathrm{~b} / \mathrm{min}, \mathrm{PS}=8 \mathrm{~cm} \mathrm{H} \mathrm{H}_{2} \mathrm{O} \text { then } \mathrm{SBT} \text { as above }\end{array}$ & Both notify doctor \\
\hline Namen, $2001^{24}$ & Daily & SBT two hour on CPAP $5 \mathrm{~cm} \mathrm{H}_{2} \mathrm{O}$ & Notify doctor \\
\hline Navalesi, $2008^{31}$ & Daily & SBT one hour on CPAP $2-3 \mathrm{~cm} \mathrm{H}_{2} \mathrm{O}, \mathrm{FIO}_{2} 0.4$ & Yes \\
\hline Piotto, $2008^{34}$ & Daily & SBT two hour on PS $7 \mathrm{~cm} \mathrm{H}{ }_{2} \mathrm{O}, \mathrm{PEEP}=5 \mathrm{~cm} \mathrm{H}_{2} \mathrm{O}, \mathrm{FIO}_{2}=0.4, \mathrm{RR}=1 \mathrm{~b} / \mathrm{min}$ & Yes \\
\hline Rose, $2008^{32}$ & None & Computer automated SmartCare stepwise reductions to PS $7 \mathrm{~cm} \mathrm{H}_{2} \mathrm{O} \&$ PEEP $5 \mathrm{~cm} \mathrm{H}_{2} \mathrm{O}$ & No \\
\hline Simeone, $2002^{33}$ & None & SIMV and PS stepwise reductions to SIMV 0 breaths/min and PS $4 \mathrm{~cm} \mathrm{H}_{2} \mathrm{O}$ & Yes \\
\hline Stahl, $2009^{36}$ & None & Computer automated SmartCare stepwise reductions to PS & Yes \\
\hline Strickland, $1993^{10}$ & None & Computer automated stepwise reductions in SIMV and PS to RR $2 \mathrm{~b} / \mathrm{min}$ and PS $5 \mathrm{~cm} \mathrm{H}_{2} \mathrm{O}$ & No \\
\hline
\end{tabular}

They ranged from a list of five to 19 criteria, and the variables measured were not consistent among studies. All studies included criteria that measured oxygenation (namely, $\mathrm{PaO}_{2}$ and $\mathrm{FIO}_{2}$ ), but not all included criteria relating to cardiovascular, neurological, inflammatory response, medication, or other factors (table 3). Readiness for weaning was assessed twice daily, ${ }^{18}$ daily, ${ }^{1623243134}$ or stated as inclusion or protocol entry criteria. ${ }^{1017323336}$

There was also considerable variation in the weaning methods (table 4). In three trials the intervention was delivered by a computer controlled weaning system: two used an automated computerised protocol delivered by Draeger EvitaXL ventilator with SmartCareTM/PS software that titrated pressure support and initiated spontaneous breathing trials, ${ }^{3236}$ and one used an early computer prototype (Supersport model 2) that titrated respiratory rate and pressure support. ${ }^{10} \mathrm{Six} \mathrm{stu-}$ dies used protocol based weaning that included a trial of spontaneous breathing. ${ }^{161823243134}$ For patients who had been ventilated for more than 72 hours, Marelich et al ${ }^{18}$ used a stepwise reduction in positive end expiratory pressure, synchronised intermittent mechanical ventilation, and pressure support before the spontaneous breathing trial. Two trials used weaning protocols consisting of stepwise reductions in synchronised intermittent mechanical ventilation and pressure support with extubation. ${ }^{3334}$ Kollef et al implemented the protocols in four intensive care units and used several different protocols: spontaneous breathing trial and extubation; synchronised intermittent mechanical ventilation reduction and extubation; pressure support reduction and extubation. ${ }^{17}$ Methods of trials of spontaneous breathing and the lower parameters stated by authors as end points before discontinuation or extubation varied greatly among trials. The duration of spontaneous breathing trial ranged from 30 to 120 minutes through a $\mathrm{T}$ tube or ventilator circuit with continuous positive airway pressure ranging from 2 to $5 \mathrm{~cm} \mathrm{H}_{2} \mathrm{O}$, with or without pressure support of 6 or $7 \mathrm{~cm} \mathrm{H}_{2} \mathrm{O}$. In pressure support weaning protocols, pressure support was reduced to levels ranging from 4 to $8 \mathrm{~cm} \mathrm{H}_{2} \mathrm{O}$ before extubation. With protocols for synchronised intermittent mechanical ventilation weaning, there was a reduction in respiratory rate to rates of between zero and six breaths a minute before a trial of spontaneous breathing or extubation. In automated weaning protocols pressure support was reduced to levels between 5 or $7 \mathrm{~cm} \mathrm{H}_{2} \mathrm{O}$ and synchronised intermittent mechanical ventilation to two breaths a minute.

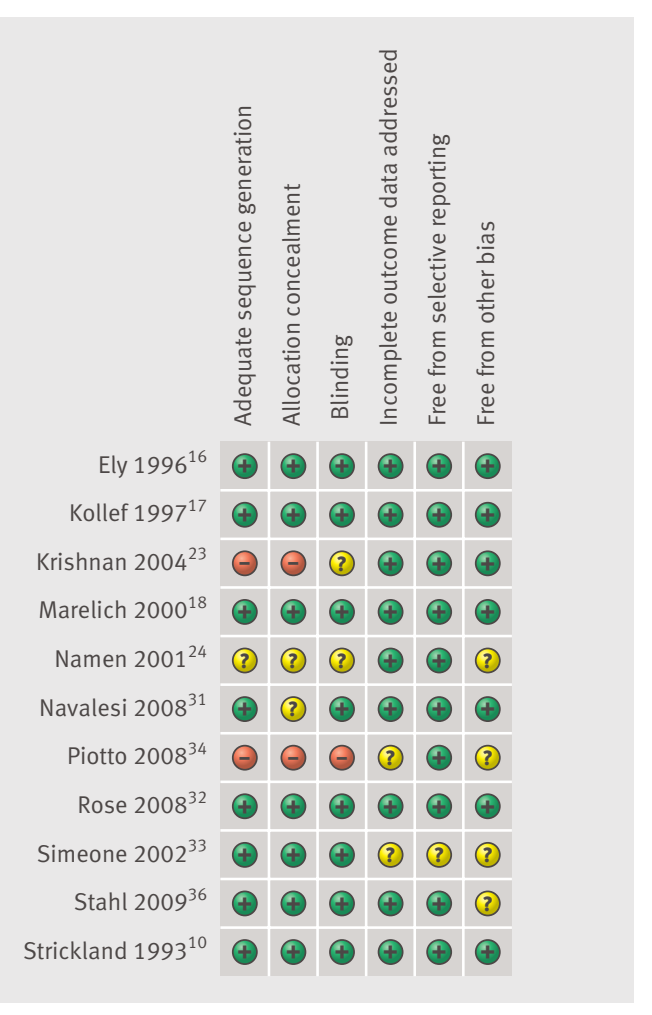

Fig 2 | Summary of risk of bias assessment 


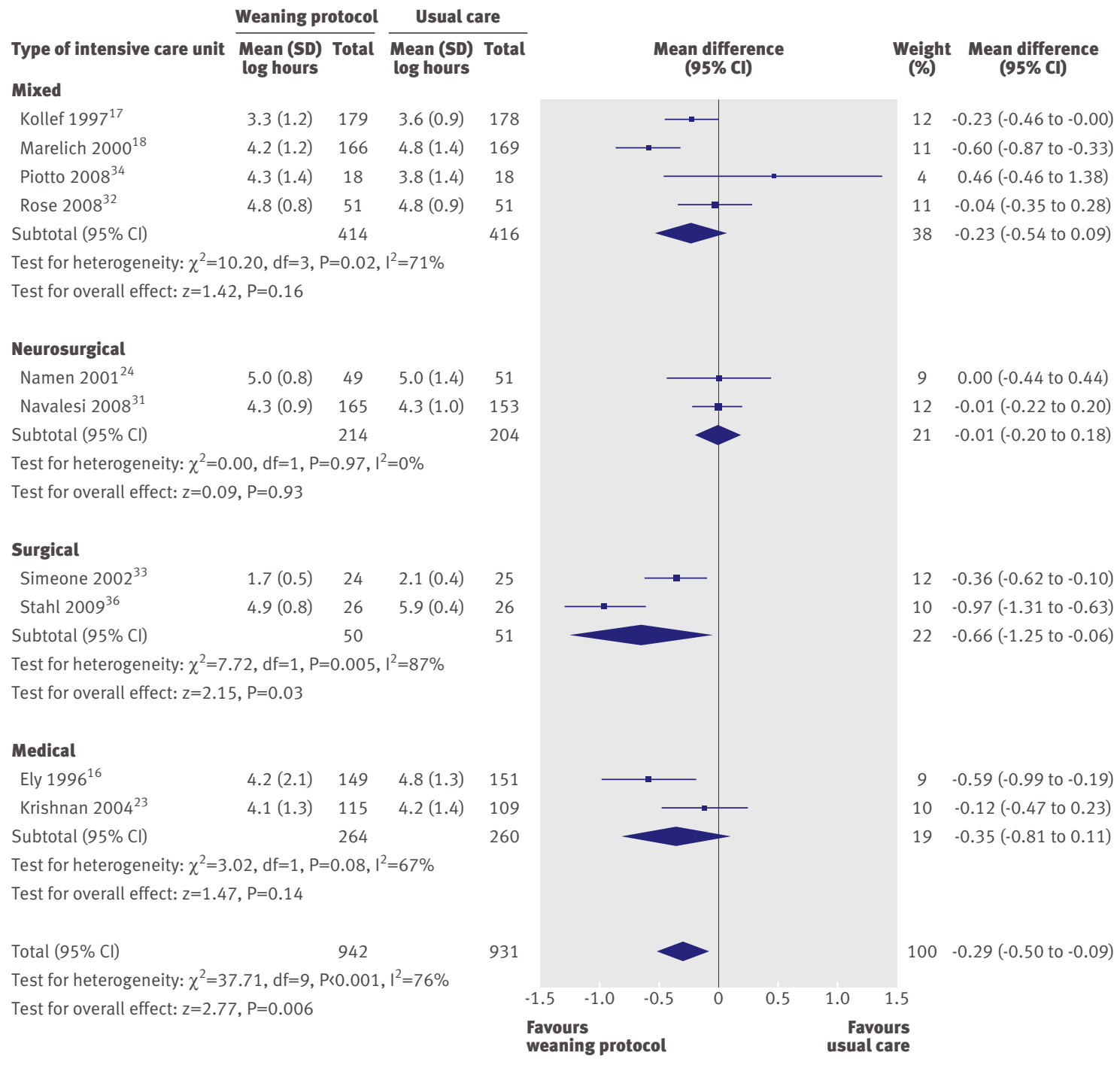

Fig 3 Duration of mechanical ventilation with and without weaning protocol; subgroup analysis by type of unit. Mean difference calculated with fixed effects model

\section{Risk of bias in included studies}

Most trials had low risk of bias across the six domains (fig 2). In eight trials, the allocation sequence was adequately generated and concealed. ${ }^{1016-1831-3336}$ Two trials used inadequate allocation generation and concealment: one allocated by using odd and even hospital numbers, ${ }^{23}$ and one allocated sequentially on recruitment. ${ }^{34}$ The remaining trial did not report the method used, and we were unable to obtain this information. ${ }^{24}$ Given the nature of the intervention, blinding of participants and staff to the intervention is not feasible, but in seven trials the outcome assessors were independent from the individuals administering the intervention: this was confirmed in publications ${ }^{10} 17$ and through personal communication with authors. ${ }^{161831-3336}$ Blinding of outcome assessors was unclear in one study, ${ }^{23}$ not done in one study, ${ }^{34}$ and could not be confirmed in one study despite attempts to obtain this information. ${ }^{24}$ Most trials reported complete outcome data: two trials insufficiently reported on recruitment, attrition, and exclusion to permit judgment. ${ }^{3334}$ Eight trials published the weaning protocol, ${ }^{1016-1823243134}$ and two described the automated computer system ${ }^{3236}$ and reported all pre-specified outcomes: one trial published the weaning algorithm but did not pre-specify outcomes so there was insufficient information to permit a judgment. ${ }^{33}$ Seven trials seemed free from "other sources of bias" as defined in the Cochrane Collaboration's domain based evaluation, ${ }^{1016-18233132}$ two were stopped early for ineffectiveness, ${ }^{2436}$ one reported unsubstantiated findings, ${ }^{33}$ and one was unpublished so there was insufficient information to permit a judgment. ${ }^{34}$ Five studies conducted a priori calculations of sample size, ${ }^{1724313436}$ two studies mentioned power calculations but were unclear, ${ }^{1823}$ and four studies did not mention this. ${ }^{10163233}$

\section{Effects of interventions}

\section{Total duration of mechanical ventilation (hours)}

Ten trials reported on the total duration of mechanical ventilation. ${ }^{16-18232431-3436}$ One trial did not report on this outcome measure as the trial lasted only 48 hours for each patient. ${ }^{10}$ The pooled result for duration of 


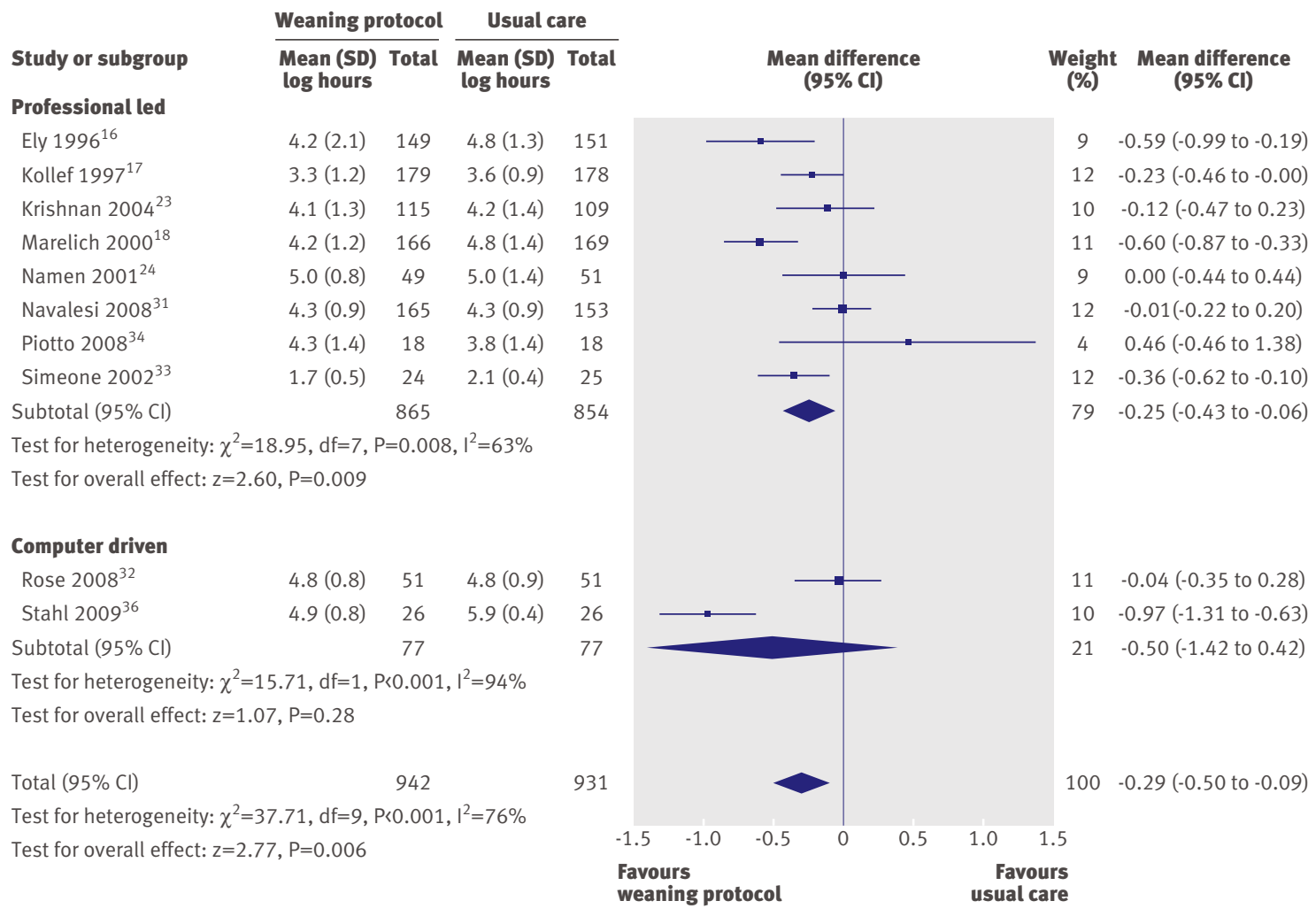

Fig 4 | Duration of mechanical ventilation with and without weaning protocol; subgroup analysis by type of approach. Mean difference calculated with fixed effects model

mechanical ventilation, with the random effects model because of significant substantial heterogeneity $\left(\mathrm{I}^{2}=76 \%, \mathrm{P}=0.0001\right)$, showed that weaning protocols were associated with significantly reduced mean log total duration of mechanical ventilation (mean log $-0.29,95 \%$ confidence interval -0.5 to -0.09 ; $\mathrm{P}=0.006)$, corresponding to a reduction of $25 \%(9 \%$ to $39 \%$ ) in the geometric mean (fig 3).

We performed a subgroup analysis to assess the impact of type of intensive care unit on the total duration of mechanical ventilation (fig 3). The subgroups were small, with two to four studies in each, and included mixed units that incorporated medical, surgical and trauma patients; neurosurgical units; and surgical units and medical units. The neurosurgical intensive care unit subgroup was introduced post hoc because we were unaware of these specific studies when writing the protocol and their weaning progress is different to other groups of patients because of neurological impairment. Pooled analysis of the four trials in the mixed intensive care unit group ${ }^{17183234}$ showed a non-significant reduction in the mean log in the weaning protocol group (mean $\log -0.23,-0.54$ to 0.09 ; $\mathrm{P}=0.16)$, corresponding to a reduction of $21 \%(-9 \%$ to $42 \%)$ in the geometric mean. Pooled analysis of the two neurosurgical studies ${ }^{2431}$ also showed a non-significant reduction in the mean log in the weaning protocol group $(-0.01,-0.2$ to $0.18 ; \mathrm{P}=0.93)$, corresponding to a reduction of $1 \%(-20 \%$ to $18 \%)$ in the geometric mean. The surgical intensive care units ${ }^{32} 36$ showed a significant reduction in the mean log in the weaning protocol group $(-0.66,-1.25$ to $-0.06 ; \mathrm{P}=0.03)$, corresponding to a reduction of $48 \%(6 \%$ to $71 \%)$ in the geometric mean; and the two medical intensive care units ${ }^{1623}$ showed a non-significant reduction in the mean $\log (-0.35,-0.81$ to $0.11 ; \mathrm{P}=0.14)$, corresponding to a reduction of $30 \%(-12 \%$ to $56 \%)$ in the geometric mean.

We also performed a subgroup analysis to assess the impact of type of approach: professional led or computer driven (fig 4). The eight studies that used a professional led approach ${ }^{16-182324313334}$ showed a significant reduction in the mean log, favouring the weaning protocol group (mean $\log -0.25,-0.43$ to $-0.06 ; \mathrm{P}=0.009$ ), corresponding to a reduction of $22 \%(6 \%$ to $35 \%)$ in the geometric mean, and there was significant heterogeneity $\left(\mathrm{P}=0.008, \mathrm{I}^{2}=63 \%\right)$. The two studies that used a computer driven approach ${ }^{3236}$ showed a non-significant reduction in the mean log in the weaning protocol group $(-0.5,-1.42$ to $0.42 ; \mathrm{P}=0.28)$, corresponding to a reduction of $39 \%(-52 \%$ to $76 \%)$ in the geometric mean. For this outcome, the average percentage difference in geometric mean of $25 \%$ is consistent with estimates in all subgroups in both subgroup analyses (that is, it is contained within the $95 \%$ confidence intervals). Therefore, the heterogeneity cannot be explained by type of unit or type of approach.

\section{Mortality}

We found no significant differences between groups in hospital mortality (odds ratio 1.10, 0.86 to 1.41; six trials, 


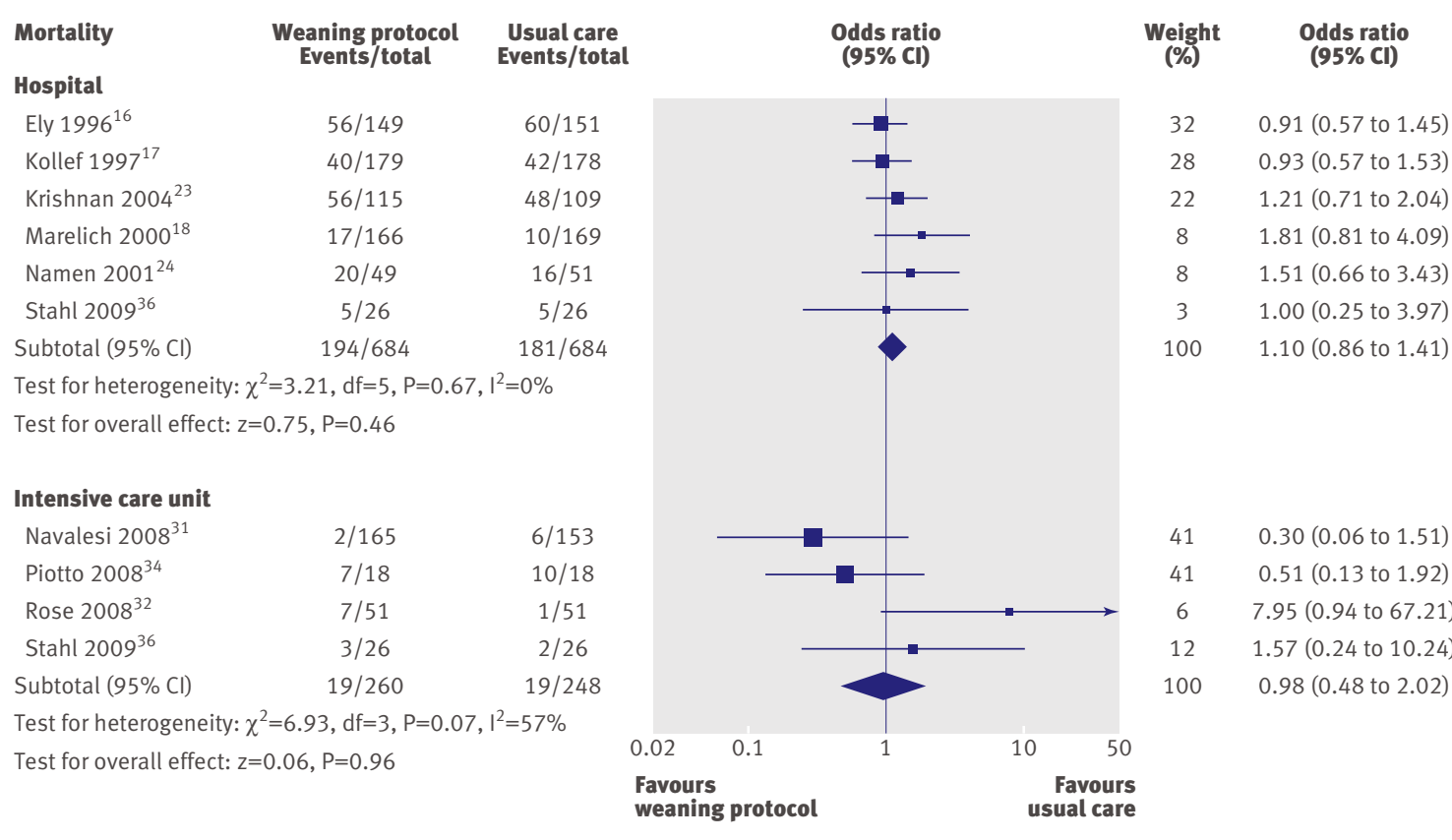

Fig $5 \mid$ Mortality in hospital and intensive care unit according to weaning with and without protocol. Odds ratio calculated with fixed effects model

$\mathrm{n}=1368)^{16-18232436}$ or mortality in the intensive care unit $(0.98,0.48 \text { to } 2.02 \text {; four trials, } \mathrm{n}=508 \text {, })^{31323436}$ (fig 5).

\section{Adverse events}

We found no significant differences between groups (table 5) in the odds of reintubation (eight trials, $\mathrm{n}=1314),{ }^{16}{ }^{172431-3436}$ self extubation (two trials, $\left.\mathrm{n}=198\right),{ }^{1624}$ and tracheostomy (six trials, $\mathrm{n}=1191$ ). ${ }^{161824313234}$ The odds of requirement for protracted weaning were significant for weaning lasting over 21 days in one trial $(n=300)^{16}$ but not in another $(\mathrm{n}=100)^{24}$ and not significant for weaning lasting over 14 days $(n=102){ }^{32}$ or seven days $(n=357) .{ }^{17}$

\section{Weaning duration (hours)}

In the random effects model for significant substantial heterogeneity $\left(\mathrm{I}^{2}=97 \%, \mathrm{P}<0.001\right)$, the pooled result for duration of weaning (six trials, $\mathrm{n}=834)^{101618323436}$ showed that weaning per protocol significantly reduced the mean $\log$ by an average of 1.52 (mean $\log -1.52,-2.66$ to $-0.37 ; \mathrm{P}=0.009)$, corresponding to a reduction of $78 \%$ (31\% to $93 \%$ ) in the geometric mean (fig 6).

Length of stay in intensive care unit (hours)

Eight trials reported on length of stay in the intensive care unit (fig 7), ${ }^{16232431-3436}$ and there was no statistical heterogeneity among studies $\left(\mathrm{I}^{2}=0 \%\right)$. Two trials showed a significant reduction in length of stay in the weaning protocol group, ${ }^{233}$ and six did not. The pooled estimate, however, was significant (mean log $-0.11,-0.21$ to $-0.02 ; \mathrm{P}=0.02$ ), corresponding to an average percentage difference in geometric mean of $-10 \%(-19 \%$ to $-2 \%)$.

Length of stay in hospital (days)

Weaning per protocol produced no significant reduction in mean hospital length of stay in four trials (fig 8). ${ }^{16172432}$ There was minimal heterogeneity $\left(\mathrm{I}^{2}=11 \%\right)$ (mean $\log -0.01,-0.11$ to $0.1 ; \mathrm{P}=0.9$, corresponding to an average percentage difference in geometric mean of $-1 \%,-11 \%$ to $10 \%)$.

\section{Economic costs}

Three trials from the US evaluated economic costs. There were no significant differences between groups for intensive care unit costs ${ }^{1624}$ (mean difference $\$ 3600$ (£2300, €2700), $-\$ 1228$ to $\$ 1948 ; \mathrm{P}=0.66$ ) or hospital costs $^{161724}$ (\$-590, $-\$ 467$ to $\left.\$ 349 ; \mathrm{P}=0.78\right)$.

\section{Sensitivity analyses}

Exclusion of studies with a high risk of bias ${ }^{2334}$ from the analyses did not change the effects observed in the primary analysis for duration of mechanical ventilation and weaning duration. Similarly, analysis of the un-logged data for studies reporting total duration of mechanical ventilation (10 trials, $\mathrm{n}=1873$ ), ${ }^{16-18232431-3436}$ weaning duration (six trials, $\mathrm{n}=706),{ }^{101618323436}$ length of stay in intensive care (eight trials, $\mathrm{n}=1256),{ }^{16232431-3436}$ and length of stay in hospital (four trials, $n=859$ ) ${ }^{16172432}$ did not change the effects observed in the primary analysis.

\section{DISCUSSION}

\section{Principal findings}

In this systematic review we assessed evidence from 11 trials on the effect of weaning protocols on the duration of mechanical ventilation in critically ill adults. We found that use of weaning protocols was associated with significant reductions in geometric mean values of $25 \%$ for the total duration of mechanical ventilation; $78 \%$ for weaning duration; and $10 \%$ for length of stay in intensive care. We recognise that results reported in percentage geometric mean values are difficult to 
Table 5 Summary of adverse events associated with weaning from mechanical ventilation with and without weaning protocol in critically ill adults on mechanical ventilation

\begin{tabular}{|c|c|c|}
\hline Adverse event & $\begin{array}{l}\text { No of patients with events/total } \\
\text { No of events }\end{array}$ & Odds ratio $(95 \% \mathrm{Cl})$, P value \\
\hline Reintubation ${ }^{16} 172431-3436$ & 1314 & $0.76(0.40$ to 1.42$), P=0.39$ \\
\hline Self extubation $^{16}$ & 300 & 0.40 (0.08 to 2.08$), P=0.25$ \\
\hline Self extubation ${ }^{24}$ & 100 & 0.50 (0.09 to 2.86$), P=0.68$ \\
\hline Tracheostomy ${ }^{161824313234}$ & 1191 & 0.74 (0.45 to 1.22$), P=0.24$ \\
\hline \multicolumn{3}{|l|}{ Protracted weaning (days): } \\
\hline$>21^{16}$ & 300 & 0.42 (0.19 to 0.96$), P=0.04$ \\
\hline $221^{24}$ & 100 & 0.18 (0.02 to 1.63$), P=0.21$ \\
\hline$>14^{32}$ & 102 & $0.68(0.20$ to 2.31$), P=0.54$ \\
\hline$>7^{17}$ & 357 & $0.63(0.35$ to 1.15$), P=0.13$ \\
\hline
\end{tabular}

interpret clinically. To illustrate these findings in mean differences that are clinically relevant we can use data on ventilation times from a large epidemiological study $(\mathrm{n}=5183)$ of characteristics and outcomes in patients receiving mechanical ventilation. ${ }^{50}$ The mean duration of mechanical ventilation in this study was 144 hours. The corresponding risk for a weaning protocol is the mean that one would expect based on the effect estimates in this review. With this method, reductions can be found in the total duration of mechanical ventilation from an assumed risk of 144 hours to a corresponding risk of 108 hours (88 to 131 hours); duration of weaning from 96 hours to 21 hours (7 to 66 hours); and length of stay in intensive care from 11 days to 10 days (9 to 11 days).

Though the data from the pooled summaries alone seem to support benefit with weaning protocols, they should be viewed with caution because of the significant heterogeneity among studies, particularly in relation to total duration of mechanical ventilation $\left(\mathrm{I}^{2}=76 \%\right)$ and duration of weaning $\left(\mathrm{I}^{2}=97 \%\right)$. We explored heterogeneity through subgroup analyses on the impact of type of intensive care unit (mixed, neurosurgical, surgical, medical) and type of approach (professional led or computer driven). We found inconsistency among results and little statistical evidence of difference in treatment effect, possibly because of the small number of studies with subgroups for analysis. The use of protocols to guide weaning did not adversely affect mortality in intensive care or hospital. We found no effect on adverse events including reintubation, self extubation, tracheostomy, and protracted weaning, though our meta-analysis was underpowered to investigate the impact of the interventions on these outcomes, which were infrequent. Furthermore, basic costing exercises in intensive care units and hospital in three US studies showed no significant difference between the alternative weaning strategies.

\section{Strengths and limitations of the review}

In this systematic review and meta-analysis of weaning protocols, most trials had sound methods and had a low risk of bias. Based on GRADE, ${ }^{51}$ however, the quality of evidence was low, mainly because of substantial variability in the effect estimates. As a result of this heterogeneity, our findings should be interpreted with caution. The methods in trials were limited by the inability to blind clinical staff to the method of weaning; therefore it is possible that clinician's decisions and actions could have been influenced, resulting in biased estimates of treatment effect. As it is not feasible to blind staff in these weaning studies, we assessed blinding of investigators collecting outcome data and found risk of bias to be low in eight of 11 included studies. Six of the 11 studies originated in the US, which could limit the extent to which findings can be generalised to other healthcare systems.

\section{Implications for clinical practice}

Ventilator weaning is a complex process, and it is not easy to isolate the reasons for heterogeneity. The discordance in results among studies could be caused by contextual factors (differences in populations of patients and usual practice within units) or intervention factors (differences in determining readiness to wean, ventilator modes, and variables used in weaning protocols). Though we attempted to examine the impact of different populations of patients on duration of mechanical ventilation by exploring types of intensive care units, we could not isolate populations in all studies because some units were "mixed" and included medical, surgical, neurosurgical, and trauma patients. Clearly, the population of patients can affect the

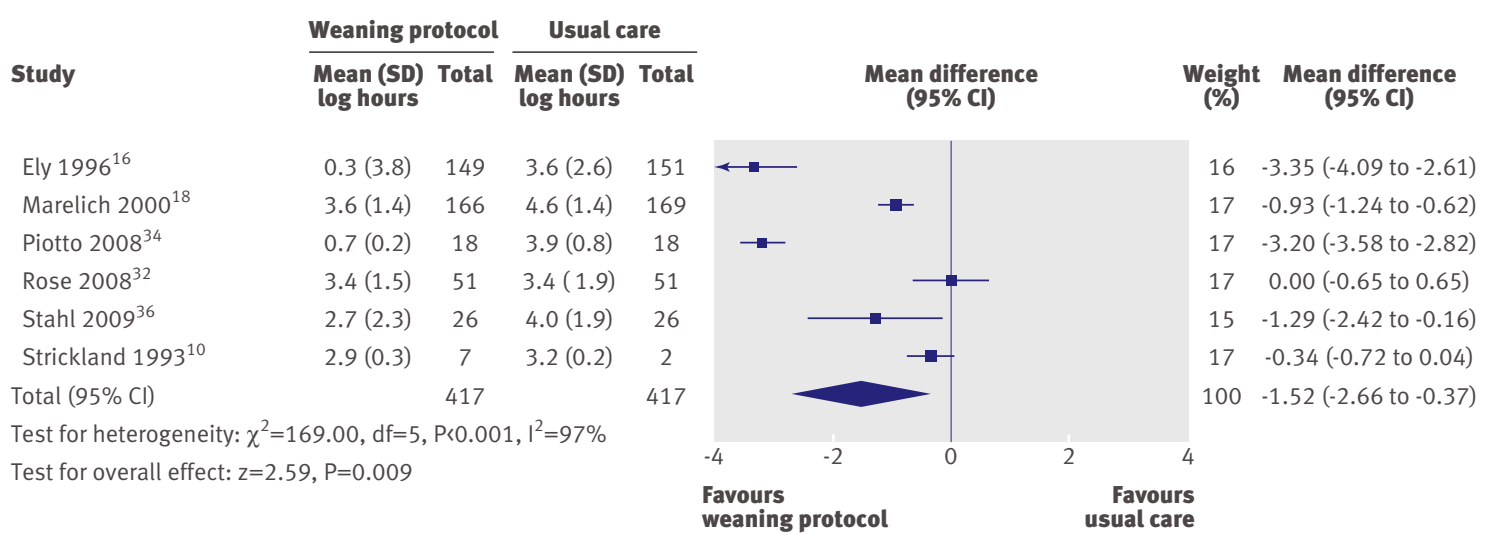




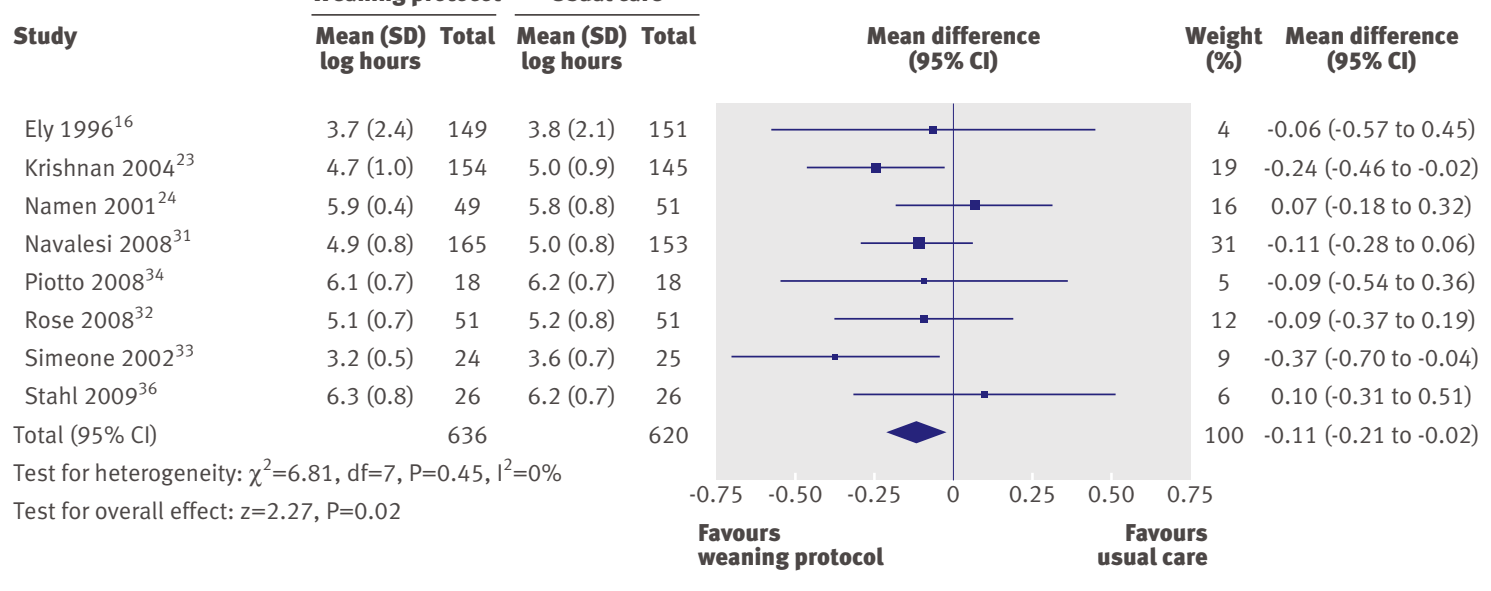

Fig 7 | Length of stay in intensive care unit with and without weaning protocol. Mean difference calculated with fixed effects model

duration of weaning. For example, weaning a surgical patient in intensive care after elective major surgery might be more straightforward than weaning a medical patient in intensive care with respiratory failure after acute exacerbation of chronic pulmonary disease. In addition, because of the wide variety of protocols used in included studies, we could not examine the impact of specific weaning protocols on specific populations of patients. What remains unknown and warrants further investigation is whether or not specific protocols are more beneficial than others in particular populations of patients.

Another important contextual factor, and one that causes controversy in studies of non-pharmacological interventions in intensive care units, is the use of the "usual care" group as a control in randomised trials. ${ }^{52}$ Usual care in intensive care units can encompass a wide variety of practices - for example, usual care might be standardised around high level evidence and thus represent best practice or it might be highly variable and include unfavourable practices. ${ }^{52}$ Consequently, if the culture of a unit is such that usual care is a standardised high level approach to weaning, albeit not formally laid out in guidelines, then it might not differ greatly from that delivered by a weaning protocol. Thus, in a trial of effectiveness, the gap between usual care and weaning with a protocol might be too small to show a significant difference between groups.

For example, Marelich et al conducted a study in one medical and one surgical/trauma intensive care unit and reported variable practice between units: the medical unit had no standardised approach to weaning whereas the surgical unit had a standardised approach to ventilator management, though extubation was based on the judgment of individual physicians. ${ }^{18}$ Thus, while combined data from both units showed a reduction in the duration of mechanical ventilation, when we analysed data separately for each unit the reduction was significant only in the medical intensive care unit where no standard approach to weaning existed. Similarly, the study by Rose et al attributed their lack of effect to usual practice in their intensive care unit, which comprised unlimited assessment of weaning by experienced autonomous critical care nurses, a 1:1 nurse to patient ratio supported by 24 hour medical staff, and twice daily rounds by an intensivist. ${ }^{32}$ The association between staffing in intensive care units and clinical outcomes has been studied previously. High intensity of medical staffing with mandatory intensivist consultation (such as that found in intensive care units in the United Kingdom) has been associated with reduced mortality and unit $^{53}$; higher doctor to patient ratios are significantly associated with higher rates of success of weaning and home discharge in patients receiving prolonged mechanical ventilation ${ }^{54}$; and an optimum number of qualified intensive care nurses led to a reduction in the duration of weaning for patients with exacerbation of chronic obstructive pulmonary disease.$^{55}$ These examples suggest that in units where the organisational culture and context supports optimum trained staff numbers, there might not be additional benefit from the use of weaning protocols compared with standardised high level approaches to weaning. Notwithstanding, full descriptions of usual care in the control groups were not provided in the included studies, and therefore we cannot be certain that this is the case.

In relation to intervention factors, there were many differences in methods among studies that could have contributed to heterogeneity. The number and type of criteria used to determine readiness to wean within protocols varied considerably (ranging from five to 17) and the broadness or restrictiveness of criteria used could have contributed to differences in results. In relation to the protocols themselves, only two used an identical weaning protocol. ${ }^{1824}$ Despite this, these trials reported conflicting results in both the duration of mechanical ventilation and weaning, possibly because of differences in the populations of patients studied or usual practice within the intensive care units.

We focused solely on the impact of weaning protocols, but it is worth noting that sedation practices influence the duration of ventilation and must be reduced length of stay in hospital and the intensive care 


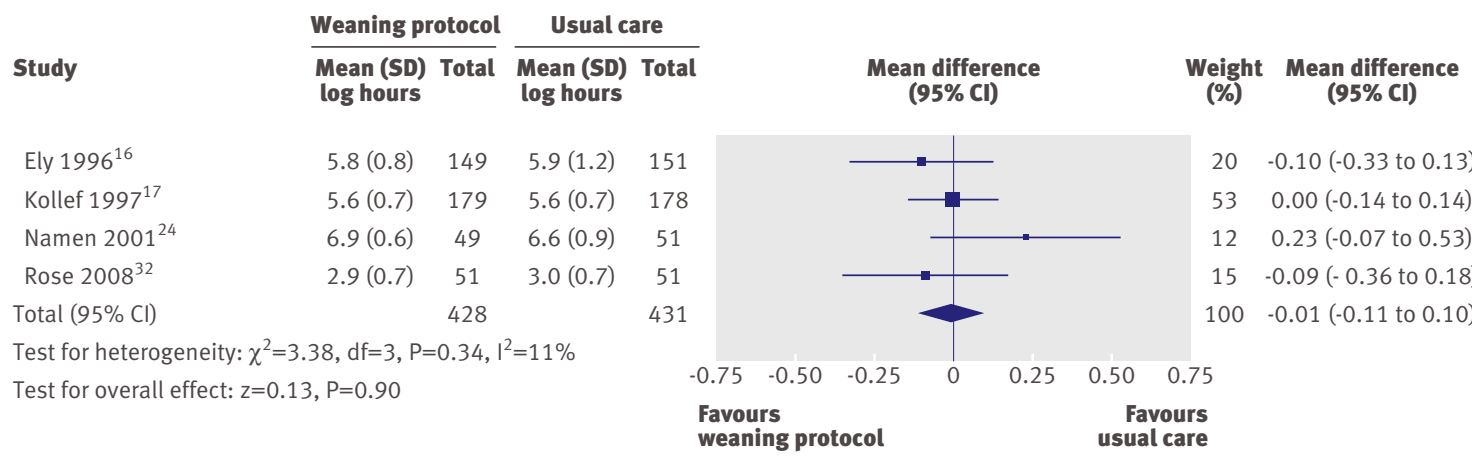

Fig 8 | Length of stay in hospital with and without weaning protocol. Mean difference calculated with fixed effects model

considered in trials of weaning protocols. The process of weaning can be affected by use of sedative agents. To this end, the manner in which sedative agents are used has been shown to be just as important as the pharmacological properties of the agents themselves. Shorter durations of ventilation and length of stay in the intensive care unit and hospital have been associated with intermittent boluses of sedation and analgesia instead of continuous infusions ${ }^{56}$ daily interruption of infusions (sedation breaks) and subsequent assessment for weaning, ${ }^{57}$ and a protocol combining daily sedation breaks with trials of spontaneous breathing. ${ }^{58} \mathrm{~A}$ recent pilot trial of a protocol for no sedation found that patients with no sedation had significantly more days without ventilation than those receiving daily sedation breaks (mean difference 4 days, 0.3 to $8 ; \mathrm{P}=0.019$ ). ${ }^{59}$ Sedation practice in intensive care units typically follows an agreed protocol or guideline ${ }^{60}$ involving assessment of the patient's response to administration of sedation/analgesia with a sedation scoring system and an algorithm that uses sedation scores to modify drug delivery. The studies included in our review provided little or no information regarding their sedation practices. To interpret changes in weaning success or time to successful weaning, future studies should include detailed information on sedation practices including the agents used, use of a sedation protocol (or lack of one) and scoring system, and whether or not daily interruptions in sedation were permitted.

\section{New developments in weaning}

Weaning and sedation protocols have contributed to the management of weaning in important ways over the past 15 years. New developments in this specialty are targeted at discontinuing invasive ventilatory support in a timely manner by using automated systems or non-invasive ventilation as a weaning strategy, and awakening and mobilising critically ill patients as soon as possible. Applying protocols to real life clinical practice can be difficult because their effectiveness depends on many factors, including their acceptability to clinicians, the workload of the intensive care unit, the requirement for frequent assessments, and monitoring to ensure compliance. Thus, automated computerised systems are increasingly being used in an attempt to improve the adaptation of mechanical support to the needs of individual patients during weaning and to reduce the time spent on ventilation, costs, and staff workload. ${ }^{61}$ Computers can continuously monitor changes in ventilation, interpret real time physiological changes, and adapt ventilation in response to these changes. As shown in this review, however, compared with usual care their efficacy in reducing the duration of mechanical ventilation has yet to be established. Nevertheless, the use of weaning protocols is increasing to the point where it is "usual practice" in many units, and we are now beginning to see more studies that compare automated weaning with weaning with a protocol. ${ }^{41434547-49}$

Non-invasive ventilation (where the endotracheal tube is removed, but the patient continues to receive ventilatory support delivered by face or nasal mask) is gaining popularity as a weaning strategy. To date the number of trials are small (around five), but a recent systematic review has shown the clinical benefit of this strategy in reducing the total duration of mechanical ventilation support in cases of difficult weaning, particularly in patients with chronic obstructive pulmonary disease. ${ }^{62}$

In patients in intensive care, mechanical ventilation and immobilisation contribute to complications such as delirium and weakness, which can affect the duration of mechanical ventilation and length of stay in intensive care and hospital. ${ }^{63-65} \mathrm{~A}$ recent randomised controlled trial of early mobilisation instigated during periods of daily sedation breaks showed significantly shorter durations of delirium (median 2 v 4 days, $\mathrm{P}=0.02$ ) and more ventilator-free days (median 23.5 v 21.1 days, $\mathrm{P}=0.05) \cdot{ }^{66}$

\section{Implications for research}

The studies we included varied in the details they presented regarding weaning protocols, the degree to which they described usual practice within their intensive care units, and the settings in which they were conducted. In many studies, neither usual weaning practice nor organisational context (for example, staffing ratios and frequency of medical rounds) were described in sufficient detail, thus it is difficult to ascertain the extent to which weaning practice differed between the experimental and control groups in the individual studies. It is important that future trials fully report the details of 


\section{WHAT IS ALREADY KNOWN ON THIS TOPIC}

Prolonged mechanical ventilation can be associated with adverse outcomes for patients

Weaning from mechanical ventilation according to standardised protocols is purported to be safe and effective in reducing the duration of mechanical ventilation, though trials have conflicting results

\section{WHAT THIS STUDY ADDS}

Compared with usual care, use of weaning protocols can reduce the duration of mechanica ventilation by $25 \%$, weaning duration by $78 \%$, and length of stay in intensive care unit by $10 \%$

As there was significant heterogeneity in included trials and most were conducted in the US, the findings might not be generalisable weaning protocols, usual weaning practice (including sedation practice), and the context into which weaning protocols are introduced (such as staffing ratios and organisation of care) as this would enable clinicians to gain a more accurate picture of the potential impact of such protocols in their own environment. Moreover, as weaning protocols are complex with multiple interrelated and interdependent components, ${ }^{67}$ well designed clinical trials should take into account other contextual and intervention factors that could have an effect. These factors need to be described in sufficient detail to enable accurate replication and comparisons among studies. We would argue that mixed methods research is necessary to fully evaluate the components of complex interventions such as weaning. Future studies of the efficacy of weaning protocols should follow a framework that incorporates process evaluation (such as that advocated by the Medical Research Council ${ }^{68}$ ) to understand how context influences outcomes and to provide insights to aid implementation in other settings.

\section{Conclusion}

Use of a weaning protocol can result in decreased total duration of mechanical ventilation, weaning duration, and length of stay in intensive care unit. The reduction in the duration of mechanical ventilation and weaning might be because of consistent application of objective criteria for determining readiness to wean and a guided approach to reducing support. Similarly, reduced length of stay in intensive care might be attributable to the reduction in mechanical ventilation. Reduced mechanical ventilation, in turn, might lead to reduced requirements for tracheostomy. In settings where objective criteria and guided approaches are already incorporated into standard weaning practice, however, further beneficial effects of weaning protocols on these outcomes might not be realised.

We thank Harald Herkner, H S Jeffrey Man, Carmen Silvia Valente Barbas, and Nathan L Pace for their help and editorial advice during the preparation of the review. The results of a Cochrane review can be interpreted differently, depending on people's perspectives and circumstances. Please consider the conclusions presented carefully. They are the opinions of review authors and are not necessarily shared by the Cochrane Collaboration. This paper is based on a Cochrane review first published in the Cochrane Library 2010 Issue 5 (www.

thecochranelibrary.com). Cochrane reviews are regularly updated as new evidence emerges and in response to feedback, and the Cochrane Library should be consulted for the most recent version of the review. Contributors: BB, FA, and PO' $\mathrm{H}$ were involved in the design of the review. $\mathrm{BB}$ developed the search strategy. BB, $\mathrm{PO} \mathrm{H}^{\mathrm{H}}, \mathrm{KB}$, and $\mathrm{FA}$ conducted the screening, and $\mathrm{BB}, \mathrm{PO}$ ' $\mathrm{H}$, and $\mathrm{KB}$ undertook assessment of risk of bias and data extraction. BB, PO'H and CC were involved in data entry and data analysis. BB wrote the first draft of the review, and all authors contributed to the various drafts of the report. BB is guarantor.

Funding: The review was funded through a Cochrane Fellowship Award for BB from the Research and Development Office, Northern Ireland, and the Health Research Board, Ireland.

Competing interests: All authors have completed the Unified Competing Interest form at www.icmje.org/coi_disclosure.pdf (available on request from the corresponding author) and declare: no support from any organisation for the submitted work, no financial relationships with any organisations that might have an interest in the submitted work in the previous three years, no other relationships or activities that could appear to have influenced the submitted work

Ethical approval: Not required

Data sharing: No additional data available.

1 Dries DJ. Weaning from mechanical ventilation. J Trauma 1997;43:372-84.

2 Mancebo J. Weaning from mechanical ventilation. Eur Resp J 1996;9:1923-31.

3 Cook DJ, Walter SD, Cook RJ, Griffith LE, Guyatt GH, Leasa D, et al. Incidence of and risk factors for ventilator associated pneumonia in critically ill patients. Ann Intern Med 1998;129:433-40.

4 Papazian L, Bregeon F, Thirion X, Gregoire R, Saux P, Denis JP, et al. Effect of ventilator-associated pneumonia on mortality and morbidity. Am J Resp Crit Care Med 1996;154:91-7.

5 Vincent IL, Bihari DJ, Suter PM, Bruining HA, White I, Nicolas-Chanoin $\mathrm{MH}$, et al. The prevalence of nosocomial infection in intensive care units in Europe (EPIC). JAMA 1995;274:639-44.

6 Meade MO, Cook DJ. The aetiology, consequences and prevention of barotrauma: a critical review of the literature. Clin Intensive Care 1995;6:166-73

7 Meade MO, Cook DJ, Kernerman P, Bernard G. How to use articles about harm: the relationship between high tidal volumes, ventilating pressures, and ventilator-induced lung injury. Crit Care Med 1997;25:1915-22.

8 Slutsky AS, Tremblay LN. Multiple system organ failure. Is mechanical ventilation a contributing factor? Am J Resp Crit Care Med 1998;157:1721-5.

9 Sahn SA, Lakshminarayan S. Bedside criteria for discontinuation of mechanical ventilation. Chest 1973;63:1002-5

10 Strickland JH Jr, Hasson JH. A computer-controlled, ventilator weaning system. A clinical trial. Chest 1993;103:1220-6.

11 Stroetz RW, Hubmayer RD. Tidal volume maintenance during weaning with pressure support. Am I Resp Crit Care Med 1995;152:1034-40.

12 Brochard L, Rauss A, Benito S, Conti G, Mancebo J, Rekik N, et al. Comparison of three methods of gradual withdrawal from ventilatory support during weaning from mechanical ventilation. Am J Resp Crit Care Med 1994;150:896-903

13 Esen F, Denkel T, Telci L, Kesecioglu J, Tütüncü AS, Akpir K, et al. Comparison of pressure support ventilation (PSV) and intermittent mandatory ventilation (IMV) during weaning in patients with acute respiratory failure. Adv Exp Med Biol 1992;317:371-6.

14 Esteban A, Frutos F, Tobin MJ, Alia I, Solsona JF, Valverdu I, et al. A comparison of four methods of weaning patients from mechanical ventilation. Spanish Lung Failure Collaborative Group. N Engl J Med 1995;332:345-50.

15 Murtagh D, Baum N. Protocols put more pennies in your practice pockets or protocols lead to practice improvement. 2010. www. neilbaum.com.

16 Ely EW, Baker AM, Dunagan DP, Burke HL, Smith AC, Kelly PT, et al. Effect on the duration of mechanical ventilation of identifying patients capable of breathing spontaneously. $N$ Engl J Med 1996;335:1864-9.

17 Kollef MH, Shapiro SD, Silver P, St John RE, Prentice D, Sauer S, et al. A randomized, controlled trial of protocol directed versus physiciandirected weaning from mechanical ventilation. Crit Care Med 1997;25:567-74.

18 Marelich GP, Murin S, Battistella F, Inciardi J, Vierra T, Roby M. Protocol weaning of mechanical ventilation in medical and surgical patients by respiratory care practitioners and nurses: effect on weaning time and incidence of ventilator-associated pneumonia. Chest 2000;118:459-67.

19 Hendrix H, Kaiser ME, Yusen RD, Merk J. A randomized trial of automated versus conventional protocol-driven weaning from 
mechanical ventilation following coronary artery bypass surgery. Euro J Cardiothorac Surg 2006;29:957-63.

20 Burns KEA, Lellouche F, Lessard MR. Automating the weaning process with advanced closed-loop systems. Intensive Care Med 2008;34:1757-65.

21 Rose L, Presneill J], Cade JF. Update in computer-driven weaning from mechanical ventilation. Anaesth Intensive Care 2007;35:213-21.

22 Cook D, Meade M, Guyatt G, Griffith L, Booker L. Criteria for weaning from mechanical ventilation. Evidence report/technology assessment No 23. AHRQ Publication No 01-E005, 2000.

23 Krishnan JA, Moore D, Robeson C, Rand CS, Fessler HE. A prospective, controlled trial of a protocol-based strategy to discontinue mechanical ventilation. Am J Resp Crit Care Med 2004;169:673-8

24 Namen AM, Ely EW, Tatter SB, Case LD, Lucia MA, Smith A, et al. Predictors of successful extubation in neurosurgical patients. Am J Resp Crit Care Med 2001;163:658-64.

25 Randolph AG, Wypij D, Venkataraman ST, Hanson JH, Gedeit RG, Meert KL, et al. Effect of mechanical ventilator weaning protocols on respiratory outcomes in infants and children. JAMA 2002;288:2561-8.

26 Lawton R, Parker D. Procedures and the professional: the case of the British NHS. Soc Sci Med 1999;48:353-61.

27 Blackwood B, Alderdice F, Burns KEA, Cardwell CR, Lavery G, O'Halloran P. Protocolized versus non-protocolized weaning for reducing the duration of mechanical ventilation in critically ill adult patients (review). Cochrane Database Syst Rev. 2009;5:CD006914.

28 Higgins JPT, Altman DG. Assessing risk of bias in included studies. In Higgins JPT, Green S, eds. Cochrane handbook for systematic reviews of interventions. Version 5.0.2. Cochrane Collaboration, 2009.

29 Higgins JPT, Green S, eds. Cochrane handbook for systematic reviews of interventions. Version 5.0.2. Cochrane Collaboration, 2009.

30 Higgins JP, Thompson SG. Quantifying heterogeneity in a metaanalysis. Stat Med 2002;21:1539-58.

31 Navalesi P, Frigerio P, Moretti MP, Sommariva M, Vesconi S, Baiardi $P$, et al. Rate of reintubation in mechanically ventilated neurosurgical and neurologic patients: evaluation of a systematic approach to weaning and extubation. Crit Care Med 2008;36:2986-92.

32 Rose L, Presneill JJ, Johnston L, Cade JF. A randomised, controlled trial of conventional versus automated weaning from mechanical ventilation using SmartCare TM/PS. Intensive Care Med 2008;34:1788-95.

33 Simeone F, Biagioli B, Scolletta S, Marullo ACM, Marchetti L, Caciorgna M, et al. Optimization of mechanical ventilation support following cardiac surgery. J Cardiovasc Surg 2002;43:633-41.

34 Piotto RF, Maia LN, Machado MN, Orrico SRP. Effects of the use of mechanical ventilation protocol in the coronary care unit: randomized study. Rev Bras Cir Cardiovasc 2010 (online publication ahead of print) www.rbccv.org.br/sgp/ visualizar artigo.asp? ObjSubmissao $=1 \&$ cod_versao $=3719 \&$ cod_fluxo $=2171$.

35 Higgins JPT, White IR, Anzures-Cabrera J. Meta-analysis of skewed data: combining results reported on log transformed or raw scales. Stat Med 2008;27:6072-92

36 Stahl C, Dahmen G, Ziegler A, Muhl E. Protocolised automated versus non-protocolised physician-directed weaning from mechanical ventilation: a controlled clinical trial. Intensivmed Prax 2009;46:441-6.

37 Hozo SP, Djulbegovic B, Hozo I. Estimating the mean and variance from the median, range and the size of a sample. BMC Med Res Methodol 2004;5:13.

38 Higgins JPT, Green S, eds. Cochrane handbook for systematic reviews of interventions. Version 5.0.2. Cochrane Collaboration, 2009.

39 Bland JM, Altman DG. The use of transformation when comparing two means. BMJ 1996;312:1153.

40 Review Manager (RevMan), Version 5 for Windows [computer program]. Nordic Cochrane Centre, Cochrane Collaboration, 2008.

41 Beale R. Comparison of an automated weaning programme and a standard clinical weaning protocol for weaning critically ill patients. www.controlled-trials.com/ISRCTN82559457.

42 Butler RJ, Martin C, Gwadry-Sridhar F. A cluster randomized trial to improve weaning and extubation from mechanical ventilation in community hospitals. NCT00157287. www.clinicaltrials.gov.

43 Donglemans DA, Veelo DP, Paulus F, de Mol BA, Korevar JC, Kudoga A, et al. Weaning automation with adaptive support ventilation: a randomized controlled trial in cardiothoracic surgery patients. Anesth Analg 2009;108:565-71.

44 East TD, Heermann LK, Bradshaw RL, Lugo A, Sailors RM, Ershler L, et al. Efficacy of computerized decision support for mechanical ventilation: results of a prospective multi-center randomized trial. Proc AMIA Symp 1999;251-5.
45 Lellouche F, Mancebo J, Jolliet P, Roeseler J, Schortgen F, Dojat M, et al. A multicenter randomized trial of computer-driven protocolised weaning from mechanical ventilation. Am J Resp Crit Care Med 2006;174:894-900.

46 McKinley BA, Moore FA, Sailors RM, Cocanour CS, Marquez A, Wright RK, et al. Computerized decision support for mechanical ventilation of trauma induced ARDS: results of a randomized clinical trial. J Trauma 2001;50:415-24.

47 Papirov G. Computer driven management of weaning following prolonged mechanical ventilation. 2007. www.clinicaltrials.gov. NCT00502489.

48 Scholz J. Automatic control of pressure support ventilation in surgical intensive care units. http://data.linkedct.org/page/trials/ NCT00445289.

49 Taniguchi C, Eid RC, Saghabi C, Souza R, Silva E, Knobel E, Paes AT, Barbas CS. Automatic versus manual pressure support reduction in the weaning of post-operative patients: a randomised controlled trial. Crit Care 2009;13:R6

50 Esteban A, Anzueto A, Frutos F, Alia I, Brochard L, Stewart TE, et al. Mechanical Ventilation International Study Group. Characteristics and outcomes in adult patients receiving mechanical ventilation. A 28-day international study. JAMA 2002;287:345-55.

51 Guyatt GH, Oxman AD, Kunz R, Vist GE, Falck-Ytter Y, Schünemann HJ, for the GRADE Working Group. Rating quality of evidence and strength of recommendations: what is "quality of evidence" and why is it important to clinicians? BMJ 2008;336:995-8.

52 Thompson BT, Schoenfeld D. Usual care as the control group in clinical trials of nonpharmacologic interventions. Proc Am Thorac Soc 2007;4:577-82

53 Pronovost PJ, Angus DC, Dorman T, Robinson KA, Dremsizov T, Young TL. Physician staffing patterns and clinical outcomes in critically ill patients: a systematic review. JAMA 2002;288: 2151-62.

54 Polverino E, Nava S, Ferrer M, Ceriana P, Clini E, Spada E, et al. Patients' characterization, hospital course and clinical outcomes in five Italian respiratory intensive care units. Intensive Care Med 2010;36;137-42.

55 Thorens JB, Kaelin RM, Jolliet P, Chevrolet JC. Influence of the quality of nursing on the duration of weaning from mechanical ventilation in patients with chronic obstructive pulmonary disease. Crit Care Med 1995;23:1807-15

56 Kollef MH, Levy NT, Ahrens TS, Schaiff R, Prentice D, Sherman G. The use of continuous IV sedation is associated with prolongation of mechanical ventilation. Chest 1998;14:541-8.

57 Kress JP, Pohlman AS, O'Connor MF, Hall JB. Daily interruption of sedative infusions in critically ill patients undergoing mechanical ventilation. N Engl J Med 2000;342:1471-7.

58 Girard TD, Kress JP, Fuchs BD, Thomason JWW, Schweickert WD, Pun BT, et al. Efficacy and safety of a paired sedation and ventilato weaning protocol for mechanically ventilated patients in intensive care (awakening and breathing controlled trial): a randomised controlled trial. Lancet 2008;371:126-34.

59 Strom T, Martinussen T, Toft P. A protocol of no sedation for critically ill patients receiving mechanical ventilation: a randomised trial. Lancet 2010;375:475-80.

60 Reschreiter H, Maiden M, Kapila A. Sedation practice in the intensive care unit: a UK national survey. Crit Care 2008;12: R152.

61 Lellouche F, Brochard L. Advanced closed loops during mechanical ventilation (PAV, NAVA, ASV, SmartCare). Best Pract Res Clin Anaesthesiol 2009;23:81-93.

62 Burns KEA, Adhikari NKJ, Keenan SP, Meade MO. Use of noninvasive ventilation to wean critically ill adults from invasive ventilation: a meta-analysis update. BMJ 2009;338:b1574.

63 Schweickert WD, Hall J. ICU-acquired weakness. Chest 2007;131:1541-9.

64 Ely EW, Gautam S, Margolin R, Francis J, May L, Speroff T, et al. The impact of delirium in the intensive care unit on hospital length of stay. Intensive Care Med 2001;27:1892-900.

65 Kress JP, O’Connor MF, Pohlman AS, Olson D, Lavoie A, Toledano A, et al. Sedation of critically ill patients during mechanical ventilation. A comparison of propofol and midazolam. Am / Respir Crit Care Med 1996;153:1012-8.

66 Schweickert WD, Pohlman MC, Pohlman AS, Nigos C, Pawlik AJ, Esbrook CL, et al. Early physical and occupational therapy in mechanically ventilated, critically ill patients: a randomised controlled trial Lancet 2009;373:1874-82.

67 Blackwood B. Methodological issues in evaluating complex healthcare interventions. I Adv Nurs 2006;54:612-22.

68 Medical Research Council. Developing and evaluating complex interventions: new guidance. 2008. www.mrc.ac.uk/ complexinterventionsguidance.

Accepted: 08 November 2010 